\title{
Effect of Occupational Load Specific Exercise Protocol on Cumulative Trauma Disorder of Upper Limb in Construction Workers
}

\author{
Mandar Kulkarni ${ }^{1}$, Sandeep Babasaheb Shinde ${ }^{2}$ \\ ${ }^{1}$ Department of Musculoskeletal Sciences, Krishna Institute of Medical Sciences (Deemed to \\ be University), Karad, Maharashtra, India. ${ }^{2}$ Department of Musculoskeletal Sciences, \\ Krishna Institute of Medical Sciences (Deemed to be University), Karad, Maharashtra, India.
}

\section{ABSTRACT}

\section{BACKGROUND}

Construction workers suffer major musculoskeletal problems in day to day life like back pain, altered posture, etc. One such major problem is due to overuse of upper limb. Till now studies were published on low back pain in construction workers. But, studies related to cumulative trauma disorder of upper limb are new. As majorly upper limb is used by construction workers for their work, so it is necessary to study the effect of occupational load specific exercise protocol on cumulative trauma disorder of upper limb. We wanted to study the effect of occupational load specific exercise protocol on cumulative trauma disorder of upper limb.

\section{METHODS}

In this comparative study, 42 construction workers, randomly allocated into two groups with 21 in each group with cumulative trauma disorder of upper limb were included. VAS , range of motion and manual muscle testing were the major outcome measures to assess pain intensity in construction workers with cumulative trauma disorder of upper limb. Later, data was collected, and analysis was done.

\section{RESULTS}

In group A, pain intensity was $68 \%$ before conventional exercise program whereas it was reduced to $23 \%$ after conventional exercise program. In group B, pain intensity was $69 \%$ before occupational load specific exercise program whereas it was reduced to $8 \%$ after occupational load specific exercise program. For shoulder joint, in group A, ROM was $45 \%$ before conventional exercise program whereas it was improved to $55 \%$ after conventional exercise program. In group B, ROM was $41 \%$ before occupational load specific exercise program; whereas, it improved to $59 \%$ after occupational load specific exercise program. In group A, muscle power was $44 \%$ before conventional exercise program; whereas, it improved to $56 \%$ after conventional exercise program. In group B, muscle power was $40 \%$ before occupational load specific exercise program; whereas, it improved to $60 \%$ after occupational load specific exercise program.

\section{CONCLUSIONS}

Occupational load specific exercise protocol is more effective than conventional protocol in construction workers with cumulative trauma disorder of upper limb.
Corresponding Author: Dr. Sandeep Babasaheb Shinde, Associate Professor,

Faculty of Physiotherapy, Krishna Institute of Medical Sciences, (Deemed to be University), Karad, Maharashtra, India.

E-mail: drsandeepshinde24@gmail.com

DOI: $10.14260 / j e m d s / 2020 / 349$

Financial or Other Competing Interests: Financial or Other Competing Interests: Dr. Shinde reports non-financial support from Krishna Institute of Medical Sciences, Deemed to be University, Karad. Dr. Kulkarni Reports non-financial support from Krishna Institute of Medical Sciences, Deemed to Be University, Karad.

How to Cite This Article:

Kulkarni M, Shinde SB. Effect of occupational load specific exercise protocol on cumulative trauma disorder of upper limb in construction workers. J. Evolution Med. Dent. Sci. 2020;9(20): 1599-1603, DOI:
Submission 06-03-2020,

Peer Review 21-04-2020,

Acceptance 27-04-2020,

Published 18-05-2020.

\section{KEY WORDS}

Cumulative Trauma Disorder, Construction Workers, Pain, Muscle Strength 


\section{BACKGROUND}

The phrase "work can be hazardous to your health" may be true when a person is exposed with repeated musculoskeletal injury because of repetitive motions while performing job tasks. ${ }^{1}$ Repetitive, sustained or forceful motions may compromise the functioning of the soft tissues producing compression of the peripheral nerves leading to a group of cumulative trauma disorders (CTD's). These disorders are also known as repetitive strain disorders, overuse syndrome and repetitive motor disorder. This causes a number of relatable conditions developing from overuse of the joints or soft tissue structures of the upper extremity. ${ }^{2}$ Cumulative trauma disorders are defined as disorders of the nerves, muscles, tendons and bones that are aggravated by repeated movements. Some conditions that are commonly referred to CTD'S are carpel tunnel syndrome, tenosynovitis, tendinitis, epicondylitis, peritendinitis and cervical syndrome. ${ }^{3}$

Cumulative trauma disorder of upper limb are a major problem facing occupational industry. ${ }^{4}$ The disorders are expensive to the employee, the worker and the society in terms of time lost from work, productivity losses, lower employee mode, increased work turnover and resulting disability. ${ }^{5}$ The primary problem in upper extremity CTD's is stressful by forceful and highly repetitive arm movements and posture. ${ }^{6}$ Activities related with the onset of CTD may develop from regular movements that include repetitive activities such as gripping and reaching. These movements are prone to be hazardous if they are repeated in forceful and awkward manner without any rest or enough recovery time ${ }^{7}$. When the recovery time is not enough and when high repetitive is merged with forceful and awkward posture the workers are at risk of developing CTD ${ }^{8}$. The construction industry is known for its occupational risk and hazards and the reliable adverse health effects. ${ }^{9}$ Construction workers have more physical demanding jobs as compared to the general population, and are continuously opened up to environmental demands as well as outdoor climates. Physical load in this work consists of awkward back and neck postures, twisted and static postures, repetitive movements are all harmful to the musculoskeletal system. Musculoskeletal disorders are primarily cause of productivity loss of work 10, functional impairment 11 and permanent disability 12 in construction workers. Workers in various construction occupations are at risk for various work related CTD's $^{13}$. This is mainly due to various biomechanical risk factors. Workers involved in repetitive work tasks need to be taught the proper way to use their upper extremities so that the risk of developing the CTD's is reduced. ${ }^{14}$

As physical therapists are experts in job analysis, exercise therapy, biomechanics and pain management, they need to be more aware of the education strategies on to the treatment and prevention of their injuries. Education about work activities is also implacable to have home making tasks and recreational pursuits, as these movements may give up themselves to stressful conditions. ${ }^{15}$

So, this article reviews the treatment strategies for cumulative trauma disorders of upper limb in construction workers which can help them to prevent further occurring injuries.

\section{METHODS}

This comparative study was done to find the effect of occupational load specific exercise protocol on cumulative trauma disorder of upper limb in construction workers. This study was carried out in Karad population. An approval of the study was obtained from the institutional ethical committee of Krishna Institute of Medical Sciences Deemed University. The purpose of the study was explained to the participants and consent form was taken. 42 construction workers having cumulative trauma disorder of upper limb were taken from Karad for the study. The inclusion criteria were workers working more than 5 years in construction work, having age group in between 30 to 40 years, both males and females and having nature of work as brick slayer and manual labourer. The exclusion criteria were those construction workers who had recent trauma to upper limb, having diabetes, recent fracture to upper limb and other neuromuscular disorder. Visual Analogue Scale (VAS) was the outcome measure taken for assessing pain intensity in construction workers with cumulative trauma disorder of upper limb. Further, 42 construction workers were divided into two groups each having 21 workers.

Conventional physiotherapy protocol was given to group A which included RICE protocol i.e. rest, ice, compression, elevation, Ultrasound and Stretching whereas occupational load specific exercise protocol was given to group B which included RICE protocol, Ultrasound along with Pain Release Phenomenon and ergonomic advice ${ }^{16}$. Isotonic and Isometric exercises were given to improve the muscle strength and endurance of the respective joints. In Pain Release Phenomenon, joint compression, muscular contraction or stretch was used as a pain provoking stimuli and stimuli was maintained for 15 to 20 secs Pain intensity was compared through Vas Scale after giving both the protocols to the respective groups. Then, statistical analysis and interpretation was done for each candidate to find out the effect of occupational load specific exercise protocol on cumulative trauma disorder of upper limb in construction workers.

\begin{tabular}{|c|c|c|c|}
\hline $\begin{array}{l}\text { Sr. } \\
\text { No. }\end{array}$ & $\begin{array}{c}\text { Demographic } \\
\text { Variables }\end{array}$ & $\begin{array}{c}\text { Number of } \\
\text { Participants }\end{array}$ & Percentage \\
\hline \multirow{3}{*}{1.} & Age & & \\
\hline & $25-30$ & 18 & $42.85 \%$ \\
\hline & $31-45$ & 24 & $57.14 \%$ \\
\hline \multirow{3}{*}{2} & \multicolumn{3}{|c|}{ Civilization } \\
\hline & Urban & 28 & $66.66 \%$ \\
\hline & Rural & 14 & $33.33 \%$ \\
\hline \multicolumn{4}{|c|}{ Type of Worker } \\
\hline 3 & Brickslayer & 8 & $19.04 \%$ \\
\hline & Labourer & 34 & $80.95 \%$ \\
\hline \multicolumn{4}{|c|}{ Addiction } \\
\hline 4 & Tobacco/Alcohol & 38 & $90.47 \%$ \\
\hline & Others & 4 & $9.52 \%$ \\
\hline \multicolumn{4}{|c|}{ Diet } \\
\hline 5 & Veg & 10 & $23.80 \%$ \\
\hline & Mixed & 32 & $76.19 \%$ \\
\hline \multicolumn{4}{|c|}{ Appetite } \\
\hline 6 & Increased & 38 & $90.47 \%$ \\
\hline & Adequate & 4 & $9.52 \%$ \\
\hline \multicolumn{4}{|c|}{ Demographic Variables } \\
\hline
\end{tabular}




\begin{tabular}{|c|c|c|}
\hline Duration & Goals & Treatment \\
\hline 07-Days & To decrease pain & $\begin{array}{c}\text { RICE Protocol (Rest, Ice, Compression, } \\
\text { Elevation) } \\
\text { Pain Release Phenomenon }\end{array}$ \\
\hline 7-14 days & $\begin{array}{l}\text { To decrease pain } \\
\text { To improve ROM }\end{array}$ & $\begin{array}{c}\text { RICE Protocol + Pain Release } \\
\text { Phenomenon+ Ultrasound+ Stretching }\end{array}$ \\
\hline $\begin{array}{c}\text { Day } 14-3 \\
\text { weeks }\end{array}$ & $\begin{array}{c}\text { To decrease pain } \\
\text { To improve ROM } \\
\text { To improve muscle strength } \\
\text { To improve muscle } \\
\text { endurance }\end{array}$ & $\begin{array}{c}\text { Pain Release Phenomenon } \\
\text { Isometrics- Resistant band } \\
\text { Dumbbell curls }-2 \text { sets, } 8 \text { reps } \\
\text { Stretching }\end{array}$ \\
\hline $\begin{array}{l}3 \text { weeks-6 } \\
\text { weeks }\end{array}$ & $\begin{array}{l}\text { To improve muscle strength } \\
\text { To improve muscle power }\end{array}$ & $\begin{array}{l}\text { Progressive Resisted exercises } \\
\text { Isotonic Exercises- Wall Push ups } \\
\text { Stretching }\end{array}$ \\
\hline $\begin{array}{l}6 \text { weeks-12 } \\
\text { weeks }\end{array}$ & $\begin{array}{c}\text { To maintain muscle strength, } \\
\text { power } \\
\text { and endurance }\end{array}$ & $\begin{array}{l}\text { Isometrics and Isotonics } \\
\text { Stretching }\end{array}$ \\
\hline \multicolumn{3}{|c|}{ Occupational Load Specific Exercise Protocol } \\
\hline
\end{tabular}

\section{Statistical Analysis}

1. Within Group Comparisons: Within group comparison was done by applying Paired $t$ test to pre and post training values of same group for all the outcome measures.

2. Between the Two Groups: Between the groups, comparison was done by applying Unpaired t- test to pre and post training values of same group for all the outcome measures.

\section{RESULTS}

\begin{tabular}{|ccccc|}
\hline Group & Mean & Standard Deviation & t Value & P Value \\
Pain group A: Pre test & 6.5 & 1.144 & 11.90 & $<0.0001$ \\
Pain group A: Post test & 2.2 & 1.232 & & \\
Pain group B: Pre test & 6.5 & 0.9591 & 21.084 & $<0.0001$ \\
Pain group B: Post test & 0.7 & 0.8691 & & \\
\hline & Table 1. Pain Intensity & & \\
\hline
\end{tabular}

\begin{tabular}{|cccccc|}
\hline Groups & Joints & \multicolumn{2}{c|}{ Mean \pm SD } & \multirow{2}{*}{ t } & P \\
& & Pre-Test & Post test & & $<0.0009$ \\
Group A & Shoulder & $6.901 \pm 1.126$ & $11.20 \pm 2.114$ & 4.365 & $<0.00178$ \\
& Elbow & $10.66 \pm 1.846$ & $10.17 \pm 2.589$ & 2.744 & $<0.017$ \\
& Wrist & $9.57 \pm 1.421$ & $4.716 \pm 2.963$ & 3.046 & 0.0102 \\
& Shoulder & $13.04 \pm 1.469$ & $17.02 \pm 2.584$ & 6.044 & $<0.0001$ \\
Group B & Elbow & $21.35 \pm 1.869$ & $11.07 \pm 2.116$ & 6.050 & $<0.0001$ \\
& Wrist & $11.12 \pm 1.872$ & $7.93 \pm 2.411$ & 6.416 & $<0.0001$ \\
\hline \multicolumn{7}{c}{ Table 2. Range of Motion } \\
\end{tabular}

\begin{tabular}{|ccccc|}
\hline Groups & \multicolumn{2}{c|}{ Mean \pm SD } & T Value & P Value \\
Group A & $0.70 \pm 0.566$ & $0.43 \pm 0.651$ & 4.760 & $<0.0001$ \\
Group B & $0.79 \pm 0.647$ & $0.53 \pm 0.766$ & 6.60 & $<0.0001$ \\
\hline \multicolumn{5}{c}{ Table 3. Manual Muscle Testing } \\
\hline \multicolumn{5}{c}{} \\
\hline
\end{tabular}

After analysing the data, significant effect was found on the population who followed the occupational load specific exercise protocol compared to conventional protocol. The results were as follows,

\section{Pain Intensity}

In group with conventional protocol standard deviation was 1.144 and 1.232 respectively. $P$ value was $<0.0001$ which was found to be extremely significant. $T$ value was 11.90 . In group with occupational load specific exercise protocol. Standard deviation was 0.9591 and 0.8691 respectively. $\mathrm{P}$ value was < 0.0001 which was found to be extremely significant. $T$ value was 21.084. By comparing the values, occupational load specific exercise protocol was found to be effective than conventional protocol.

\section{Range of Motion}

\section{Shoulder Joint}

In group with conventional protocol, standard deviation was 6.901 and 11.206 respectively. P value was $<0.0009$ which was found to be extremely significant. $\mathrm{T}$ value was 4.365. In group with occupational load specific exercise protocol. Standard deviation was 13.048 and 17.027 respectively. $\mathrm{P}$ value was $<0.0001$ which was found to be extremely significant. $\mathrm{T}$ value was 6.044 . By comparing the values, occupational load specific exercise protocol was found to be effective than conventional protocol.

\section{Elbow Joint}

In group with conventional protocol, standard deviation was 10.661 and 10.177 respectively. $P$ value was $<0.0178$ which was found to be considered significant. T value was 2.744. In group with occupational load specific exercise protocol. Standard deviation was 21.353 and 11.073 respectively. P value was $<0.0001$ which was found to be extremely significant. $\mathrm{T}$ value was 6.040 . By comparing the values, occupational load specific exercise protocol was found to be effective than conventional protocol.

\section{Wrist Joint}

In group with conventional protocol, standard deviation was 9.574 and 4.716 respectively. $P$ value was $<0.0102$ which was found to be considered significant. $T$ value was 3.046. In group with occupational load specific exercise protocol. Standard deviation was 11.127 and 7.937 respectively. $\mathrm{P}$ value was $<0.0001$ which was found to be extremely significant. $\mathrm{T}$ value was 6.416 . By comparing the values, occupational load specific exercise protocol was found to be effective than conventional protocol.

\section{Manual Muscle Testing}

In group with conventional protocol, standard deviation was 0.7003 and 0.4364 respectively. $\mathrm{P}$ value was $<0.0001$ which was found to be extremely significant. $\mathrm{T}$ value was 4.760 . In group with occupational load specific exercise protocol. Standard deviation was 0.7928 and 0.5390 respectively. $P$ value was $<0.0001$ which was found to be extremely significant. $\mathrm{T}$ value was 6.601 . By comparing the values, occupational load specific exercise protocol was found to be effective than conventional protocol.

\section{DISCUSSION}

The study is about the effect of occupational load specific exercise protocol on cumulative trauma disorder of upper limb in construction workers. Cumulative trauma disorder is a term used to denote damage ad pain caused by repetitive movement and overuse. Repetitive strain injury impacts muscles, nerves, ligaments and tendons. These types of injuries can be caused by improper technique or overuse. Therefore, it is important to prevent these injuries by maintaining neutral body positions so that workers perform more efficiently and work more comfortably. The objective of 
this study was to find the effect of occupational load specific exercise protocol on cumulative trauma disorder of upper limb in construction workers and compare it with the conventional exercise program. Study was carried on 42 construction workers who were divide in two groups (21 each) and over a period of 12 weeks occupational load specific exercise program was given and recorded and compared with the conventional exercise program. Group 1 was instructed to follow their routine conventional exercise program (for example RICE protocol, ultrasound, hands on stretching etc). Group 2 the exercise protocol was designed which included pain release phenomenon, RICE protocol, ultrasound, hands on stretching. Isotonic and Isometric exercises were given to improve the muscle strength and endurance of the respective joints. Construction safety is very necessary to ensure safe environment for the workers. All construction workers need to be educated on safety at each construction site to reduce injury. Significant change was found in between 2 groups by both exercise program (conventional as well occupational load specific).

In group A, pain intensity was $68 \%$ before conventional exercise program whereas it was reduced to $23 \%$ after conventional exercise program. In group B, pain intensity was $69 \%$ before occupational load specific exercise program whereas it was reduced to $8 \%$ after occupational load specific exercise program. For Shoulder Joint, in group A, ROM was $45 \%$ before conventional exercise program whereas it was improved to $55 \%$ after conventional exercise program. In group B, ROM was $41 \%$ before occupational load specific exercise program whereas it was improved to $59 \%$ after occupational load specific exercise program. For Elbow Joint, in group A, ROM was $44 \%$ before conventional exercise program whereas it was improved to $56 \%$ after conventional exercise program. In group B, ROM was $36 \%$ before occupational load specific exercise program whereas it was improved to $64 \%$ after occupational load specific exercise program. For Wrist Joint, in group A, ROM was $42 \%$ before conventional exercise program whereas it was improved to $58 \%$ after conventional exercise program. In group B, ROM was $36 \%$ before occupational load specific exercise program whereas it was improved to $64 \%$ after occupational load specific exercise program. In group A, muscle power was $44 \%$ before conventional exercise program whereas it was improved to $56 \%$ after conventional exercise program. In group B, muscle power was $40 \%$ before occupational load specific exercise program whereas it was improved to $60 \%$ after occupational load specific exercise program. Specifically, designed exercise program is very important to address all possible needs related to muscle performance and injury prevention. ${ }^{16}$ Hydrotherapy and aquatic exercises are beneficial for chronic painful musculoskeletal publication. ${ }^{17}$

To summaries this a study was carried to find the effect of occupational load specific exercise protocol on cumulative trauma disorder of upper limb in construction workers. Forty-two construction workers were included and divided into two groups of twenty-one each. Group one followed their conventional regular exercises and group two occupational load specific exercise program was designed and was followed for a period of 12 weeks. Extremely significant results were found with $\mathrm{p}$ value $<0.0001$. Physiotherapists play an important role and can design various protocols to get rid of this problem.

\section{CONCLUSIONS}

The study was carried to find the effect of occupational load specific exercise protocol on cumulative trauma disorder of upper limb in construction workers. The data was assessed, and a significant decline was found in pain intensity which proved that occupational load specific exercise program was more effective than conventional exercise program with $\mathrm{P}$ value $<0.0001$ which was extremely significant.

\section{REFERENCES}

[1] Aja D. Occupational therapy on intervention for overuse syndrome. American Journal of Occupational Therapy 1991;45(8):746-50.

[2] Armstrong TJ. Ergonomics and cumulative trauma disorders. Hand Clinics 1986;2(3):553-65.

[3] Greenough CG, Fraser RD. The effects if compensation on recovery from low-back injury. Spine 1989;14(9):94755.

[4] Stocks SJ, McNamee R, Carder M, et al. The incidence of medically reported work-related ill health in the UK construction industry. Occup Environ Med 2010;67(8):574-6.

[5] Brenner H, Ahern W. Sickness absence and early retirement on health grounds in the construction industry in Ireland. Occup Environ Med 2000;57(9):61520.

[6] Village J, Ostry A. Assessing attitudes, beliefs and readiness for musculoskeltal injury prevention in the construction industry. Appl Ergon 2010;41(6):771-8.

[7] Van der Molen HF, Sluiter JK, Frings-Dresen MHW. The use of ergonomic measures and musculoskeletal complaints among carpenters and pavers in a 4.5-year follow-up study. Ergonomics 2009;52(8):954-63.

[8] Vink P, Miedema M, Koningsveld E, et al. Physical effects of new devices for bricklayers. Int J Ocuup Saf Ergon 2002;8(1):71-82.

[9] Arndt V, Rothenbacher D, Brenner H, et al. Older workers in the construction industry: results of a routine health examination and a five year follow up. Occup Environ Med 1996;53(10):686-91.

[10] Stocks SJ, McNamee R, Carder M, et al. The incidence of medically reported work-related ill health in the UK construction industry. Occup Environ Med 2010;67(8):574-6.

[11] Meerding WJ, Ijzelenberg W, Koopmanschap MA, et al. Health problems lead to considerable productivity loss at work among workers with high physical load jobs. J Clin Epidemiol 2005;58(5):517-23.

[12] Le Masters G, Bhattacharya A, Borton E, et al. Functional impairment and quality of life in retired workers of the construction trades. Exp Aging Res 2006;32(2):227-42.

[13] Brenner H, Ahern W. Sickness absence and early retirement on health grounds in the construction industry in Ireland. Occup Environ Med 2000;57(9):61520 . 
[14] De Vries HJ, Brouwer S, Groothoff JW, et al. Staying at work with chronic nonspecific musculoskeletal pain: a qualitative study of workers' experiences. BMC Musculoskelet Disord 2011;12:126.

[15] Holmstrom E, Moritz U, Engholm G. Musculoskeletal disorders in construction workers. Occupational Medicine: State of the Art Reviews 1995;10(2):295-312.
[16] Shinde SB, Varadharajulu G. Effect of therapeutic exercise programme in adults with early rheumatoid arthritis. Indian J Physiotherapy and Occupational Therpy 2017;11(3):76-80. www.ijpot.com

[17] Sawant RS, Shinde SB. Effect of hydrotherapy based exercises for chronic nonspecific low back pain. Indian Journal of Physiotherapy \& Occupational Therapy 2019;13(1):133-8. 